\title{
LA DIASPORA HAÏTIENNE: territoires migratoires et réseaux transnationaux
}

\author{
Cédric Audebert. Rennes (FR), \\ Presses Universitaires de Rennes, 2012, 195 p.
}

O fenômeno relativamente recente da entrada de milhares de imigrantes haitianos por diferentes pontos da fronteira brasileira na Amazônia, e sua posterior dispersão para diferentes localidades do território nacional, despertou em nossa sociedade o interesse pelo Haiti, a origem desses imigrantes. Muito se falou das consequências do terremoto de 2010, que dizimou a população daquele país, em particular de sua capital, Porto Príncipe, motivando o êxodo que os trouxe inesperadamente às fronteiras do Brasil. Ao lado da comoção suscitada pela emergência humanitária, outras ideias foram veiculadas, demonstrando nosso imenso desconhecimento da realidade desses migrantes, quando não o preconceito que carregamos em relação a eles. Esse livro, publicado na França, pode trazer uma visão ampla e atualizada que nos ajudaria a contextualizar esse fenômeno que agora também nos concerne. Sua leitura é oportuna, pois ele constrói uma reflexão aprofundada sobre a diáspora haitiana, desde suas origens até o momento em que, ainda sob estado de choque, se levantavam interrogações sobre o futuro da população haitiana após o terremoto.

O livro de Cédric Audebert tem por propósito justamente estudar a estruturação da imensa rede migratória haitiana espalhada em várias nações. Apoiado numa determinada concepção de diáspora, como 
resultado da ação de inúmeras correntes migratórias desencadeadas desde o século XIX no Haiti até os anos atuais, busca compreender a formação dos chamados "territórios migrantes", produto do entrelaçamento de relações que se estruturam local e transnacionalmente. Dessa forma, tenta superar a visão segmentada da emigração/imigração, a fim de passar de uma "abordagem geográfica para uma construção identitária fundada na dispersão espacial completa". Nessa diáspora, se "mantém laços duráveis unindo uma população dispersa em escala mundial e fundada num forte sentimento de pertença nacional" (p. 11). Partindo do estudo sobre os fluxos migratórios de haitianos na República Dominicana, Caribe, Guiana Francesa, Canadá, França e principalmente Estados Unidos, desenvolve-se uma análise se propondo a "compreender em que medida as representações coletivas, investindo a noção de diáspora de significações múltiplas, e por vezes contraditórias, correspondem à realidade de uma construção social espacializada, inscrita na duração" (p. 13). Temos então a construção de uma cultura diaspórica, por meio de uma memória coletiva mantida e desenvolvida nas práticas de atores transnacionais, na diversidade social de comunidades territorializadas em diferentes países e localidades, nas suas mútuas relações e recomposições espaciais, em diferentes escalas.

No primeiro capítulo, o autor refaz todo o percurso histórico da migração haitiana. Partindo da independência do Haiti, no início do século XIX, demonstra suas dificuldades em se afirmar como nação, em meio a grandes divisões internas. Num quadro de marginalização interna e internacional, verificam-se diferentes formas de migração interna como modo de resistência à tentativa de restabelecimento do sistema de "plantation". No início do século XX, a reorganização das forças internacionais colocou o Haiti na esfera de dominação dos Estados Unidos. Entre 1915 e 1934, a ocupação norte-americana levou imensos grupos de imigrantes haitianos a se inserirem na economia da "plantation" da cana-de-açúcar, como reservatório de mão-de-obra barata e abundante para países do Caribe, como República Dominicana e Cuba. Ainda na primeira metade do século XX, esse deslocamento representou uma busca de autonomia em relação à condição de subserviência no país de origem. Mas também, o meio pelo qual se constituíram as primeiras rotas e redes de migração, ensejando a aquisição de uma cultura de migração e resistência que se desenvolveu até os dias atuais. Dos anos 1950 até 1986, com a ditadura da família Duvalier, um regime de perseguição política se abateu sobre todas as classes sociais, junto a um crescente sistema de exploração e extorsão das populações rurais. Dessa forma, desencadeou-se um êxodo 
generalizado da população haitiana, atingindo desde as classes médias urbanizadas até a população rural mais pobre. Assim, a migração haitiana alargou enormemente o seu raio de alcance: do Quebec, passando por Nova York, Miami, diversas ilhas do Caribe, até os territórios ultramar franceses, como as Antilhas e a Guiana Francesa. Ao lado da exploração e repressão política, temos como causas da diáspora a forte pressão demográfica, a devastação ambiental, a desestruturação da economia rural, entre outros. Nos anos 1990 persiste a instabilidade política no Haiti, com um caos crescente da administração pública, contribuindo para tornar a emigração um fenômeno estrutural da sociedade haitiana. Enfim, a busca permanente de sair do país, depois de décadas de desilusão, desemboca numa perda de confiança no futuro do Haiti e no desejo de alargar o espaço de vida familiar, como única estratégia para construir uma alternativa de futuro.

A partir desse quadro histórico, no segundo capítulo, o autor procura recuperar como foi o tratamento político dado à migração haitiana, no Haiti e nos seus países de destino. Considerando que a posição dos haitianos nesses países é condicionada pelo lugar subalterno do Haiti na divisão internacional de trabalho, tenta recuperar em cada país como se estruturaram as políticas migratórias em relação a eles. Em geral, em países como República Dominicana, Bahamas, Antilhas ou Guiana, o efeito das políticas migratórias, ou de sua ausência, é a segregação social e a criação de obstáculos para a documentação dos haitianos: de um lado são suscetíveis de serem expulsos a qualquer momento, e de outro, a precarização de sua permanência rebaixa ainda mais o custo de sua mãode-obra. Na América do Norte, por sua vez, possuem uma trajetória mais diferenciada, conforme o perfil dos fluxos que ali chegaram. Se existem períodos de controle severos, como na chegada dos "boat peoples", entre os anos 1970 e 80, também existem casos de inserção e ascensão social. Verifica-se uma história de mobilização e organização associativa da comunidade haitiana na defesa de seus direitos nos Estados Unidos, desde os anos 1970. Tal mobilização mostra como a

geografia desta diáspora, longe de se fixar, se reatualiza permanentemente por meio das dinâmicas das redes, revelando tanto a solidariedade dos atores que a animam, como a necessidade de responder à precariedade das condições de vida. (AUDEBERT: 2012, p. 71) ${ }^{1}$.

1 Tradução livre. 
No terceiro capítulo entramos no cerne do tema do livro, o da constituição de uma "geodinâmica das redes migratórias haitianas". Diante de contextos desfavoráveis à migração, a resposta dos imigrantes foi ampliar rapidamente o raio dos fluxos, apoiados numa extensa rede de solidariedade social que se estende para além das fronteiras dos países. Os fluxos geram as redes, que por meio de seus atores reorganizam esses mesmos fluxos. O principal ator é a família extensa que se serve de seus membros dispersos para organizar o fluxo de informações e remessas, e as estratégias de inserção de seus membros em novas localidades. A partir dessa lógica da família extensa se pode entender que, mesmo se tornando transnacional, essas redes permanecem sendo regionalizadas. Cada região do Haiti tem sua própria história migratória e desenvolve seus polos de conexão. Essa solidariedade grupal vai desenhando uma geografia que evolui na medida em que vai se distribuindo em novos territórios, criando "novas dispersões e dinâmicas circulatórias inovadoras que abrem novos espaços de passagem e instalação" (p.87). Esse nexo entre determinadas regiões do Haiti e sua específica trajetória migratória constitui o que o autor chama de "campo migratório", agilizando um sistema circulatório de pessoas, mercadorias, capitais e informação. O autor exemplifica com o caso das migrações originárias do norte e nordeste do Haiti, inicialmente com os "boat people", constituindo a rede que veio a se instalar solidamente em Miami.

A instalação dos polos dessa rede transnacional em grandes centros urbanos é o tema do quarto capítulo. A diáspora significou a inserção dos imigrantes haitianos nas dinâmicas do mundo globalizado, e por meio de sua metropolização encontram o melhor modo de se organizarem como rede e otimizarem a circulação de pessoas e recursos, alargando a possibilidade de atingirem novos nichos de emprego e aproveitarem as oportunidades que surgem. Assim, o espaço migratório haitiano se articula e polariza em torno de grandes metrópoles internacionais, como Miami, Nova York, Paris, Montreal. São espaços cosmopolitas, mas também espaços sociais segmentados, marcados pela segregação residencial e diferentes níveis de diversificação social. Os haitianos normalmente se inserem por baixo da escala socioeconômica. Sua pobreza crônica e seu baixo capital social explicam as muitas dificuldades para se fazerem respeitar, interagir com outros grupos sociais e reconstruírem sua identidade. A heterogeneidade social da diáspora, se por um lado leva alguns grupos a preservarem seu status no país de adoção, por outro, cria dinâmicas de complementaridade 
entre diferentes grupos. A sinergia entre esses grupos instalados na diáspora, apesar das disparidades sociais, permite uma nova estruturação da comunidade haitiana no exterior, reformulando de maneira nova seus referenciais identitários.

O quinto capítulo trata propriamente das diferentes formas de interação entre os polos da diáspora, naquilo que chamou de "territórios diaspóricos circulatórios". O estudo aborda duas modalidades pelas quais a dinâmica da diáspora se expande: por meio das "estratégias espaciais transnacionais das Igrejas Protestantes haitianas", e o desenvolvimento de um "território circulatório do comércio informal haitiano". Após o resgate sobre como o protestantismo entrou no Haiti, por meio da ocupação norte-americana, e como ganhou uma feição endógena sem nunca se desvincular dos Estados Unidos, demonstra como rapidamente, por meio das pequenas igrejas familiares, a rede de solidariedade entre os migrantes se expande por vários pontos do Caribe e dos Estados Unidos. Entre católicos e inúmeras denominações protestantes, se opera uma verdadeira "marcação étnica das grandes metrópoles", cujo melhor exemplo é o da "Little Haiti", em Miami. Em seguida, a partir desse mesmo exemplo, mostra como concretamente se expande a rede de pequeno comércio haitiano no exterior, suas diferenciações com outras etnias presentes nessa cidade, e sua função na dinamização da solidariedade entre haitianos, em diversas localidades e países.

Os dois últimos capítulos tratam das dinâmicas de reconstrução identitária entre os haitianos dispersos por vários países, com seus recursos, limites e dilemas, considerando a importância da "integração" da diáspora no novo contexto local e global das sociedades em que se instalam. O que se tem evidenciado é a formação de uma identidade cultural de "rede", híbrida, a partir de múltiplos referenciais: local, nacional, caribenho, racial. O alargamento e a diversificação dos meios de difusão de grupos artísticos, aliados à mistura de múltiplas influências, por meio de várias mídias, fazem com que a circulação cultural se dissemine cada vez mais. Ao lado disso, nos contextos locais e nacionais em que se instalam, existem vários programas cívicos e educativos, sobretudo nos Estados Unidos, que investem na integração em ambientes pluriculturais, ao mesmo tempo em que contribuem para sua afirmação étnica. A convergência desses fluxos de formação e informação, em várias escalas, do virtual e escolar ao mercado de entretenimento, ajuda na construção de uma "identidade múltipla", como outros grupos que se constituem nos fluxos da globalização, por 
meio da circulação cultural transnacional. É nesse ambiente que se coloca a questão do futuro da diáspora, sobretudo após a catástrofe de janeiro de 2010. Existe uma contradição fundamental que deve ser vencida: a distância crescente da diáspora frente às autoridades do Haiti, por um lado, e a imbricação da dinâmica político-econômica da diáspora com seu país de origem, por outro. O reconhecimento da força emergente da diáspora deveria levar à complementariedade com novas modalidades de desenvolvimento político-social no Haiti. Se a gênese da migração se encontra na resistência à opressão e insegurança institucional que sempre caracterizaram a história haitiana, os novos tempos demandam uma reconciliação política entre o Haiti e sua diáspora. A riqueza do aprendizado político da organização comunitária no exterior, por meio de projetos que viabilizem novas formas de inserção no país de origem, deveria permitir a construção de um projeto comum, implicando a sociedade civil na sua diversidade, inclusive a contribuição dos haitianos da diáspora.

Sem dúvida, esse livro pode ser uma contribuição importante para aqueles que no Brasil buscam acompanhar os imigrantes haitianos que aqui vêm se instalando. Ele vem suprir nossa falta de informação, não só em relação ao desconhecimento a respeito do histórico da imigração haitiana, mas também quanto à complexidade que vem adquirindo o universo das migrações no mundo atual, do qual a diáspora haitiana é um dos exemplos mais marcantes. Para além de um caso de "crise humanitária", a presença dos haitianos nos lembra que estamos entrando de cheio nos fluxos da globalização, pela porta dos fundos, a fronteira da Amazônia. Se as autoridades brasileiras, nas últimas décadas, vinham se preocupando com a integração econômica com outros países da América Latina e Caribe, por meio de grandes projetos nos territórios fronteiriços, a vaga de imigrantes haitianos veio mostrar que a realidade humana que isso implica exige uma abertura de espírito muito maior.

Sidnei Marco Dornelas Comissão Episcopal para a Missão Continental e Setor Pastoral da Mobilidade Humana 